\title{
Erratum to: Fast track intervention effects on youth arrests and delinquency
}

\section{Conduct Problems Prevention Research Group}

\section{Erratum to: J Exp Criminol \\ DOI 10.1007/s11292-010-9091-7}

Footnote for Table 7 is incorrectly presented.

The corrected sentence should read: "Models also includes time and time squared; 11 pre-intervention covariates; indicators for gender, race, site, and cohort; and an indicator for whether mother has ever been arrested. The complete set of results is available on request."

The online version of the original article can be found under http://dx.doi.org/10.1007/s11292-010-9091-7.

Conduct Problems Prevention Research Group Various Universities,

USA

e-mail: jlochman@as.ua.edu 